\title{
Social support and health status in spinal cord injury
}

\author{
C A Anson PhD, ${ }^{1}$ D J Stanwyck PhD,${ }^{2} \mathrm{~J}$ S Krause PhD \\ ${ }^{1}$ Shepherd Spinal Center, 2020 Peachtree Road, N W Atlanta, Georgia 30309, USA; \\ ${ }^{2}$ Georgia State University.
}

In a mailed survey, 125 persons with spinal cord injury responded to questions on the SCI Quality of Life Index (QOLI), and the Reciprocal Social Support Scale. The results indicated that people with SCI who believe that they receive support from the community, compared to those who believed they received less support (1) perceived themselves to be better adjusted to their injury, and (2) had significantly fewer health problems (fewer spinal cysts, lower blood pressure, shorter recovery time from decubitus ulcers, less pain below the level of injury, and fewer hospital admissions). The results also showed that people who believe that they contribute to the community in some way, compared to those who believed they contributed little or nothing (1) perceived themselves to be better adjusted to their injury, and (2) had significantly fewer health problems (fewer urinary tract infections, fewer decubitus ulcers, less severe decubiti, less pain above the level of injury, and fewer hospital admissions). A community support score, a summary score of support given and received, was also related to adjustment and health.

Keywords: spinal cord injury; social support; secondary complications; health status.

\section{Introduction}

In recent decades, an increasing number of researchers have investigated the ways in which social support affects the individual. In a number of studies, the social support system of an individual has been found to have a positive impact on physical and mental health and behavior. ${ }^{1-4}$ In these studies individuals with high levels of social support were reported to have lived longer, experienced fewer or less severe illnesses, maintained new behaviors, and performed better academically.

In 1965, for example, the Human Population Laboratory surveyed 4,452 households on issues related to health and social networks. The results of a 9 year follow up study of nearly 5,000 individuals indicated that those who had been most isolated from social contacts were two to four times more likely to have died than those with broader social connections. ${ }^{1}$ Moreover, this finding was demonstrated to be independent of physical health (at the time of the survey), smoking habits, alcohol consumption, healthcare practices, physical activity, and socioeconomic status.

Fifteen years later, Sosa and his colleagues ${ }^{5}$ studied the effect of social support on the outcomes of labor and delivery. The research was conducted in a hospital in Guatemala where family and friends are not normally allowed to accompany an expectant mother; however, the research team was permitted to provide 33 women with a companion who remained with them during the birth process. Eighty percent of the women $(n=103)$ who were without companions experienced serious medical complications in contrast to only $39 \%$ of those in the experimental group. The delivery time of the two groups was also significantly different-average duration of labor for the women who were alone was 19.3 hours, while for those with a companion present, it was 8.7 hours.

More recently, McClellan et al ${ }^{6}$ reported that, for patients with end-stage renal disease (ESRD), lower risk of mortality was associated with social support. In this 
report, however, the researchers found unique variance associated with patients' reports of their having given, rather than only received, social support. Previous studies have also shown social support (received) to be influential in rehabilitation progress and complications experienced by spinal cord injured (SCI) individuals. ${ }^{7}$

Although the research cited above has related various health outcomes to social support, too little is known regarding the patterns of health-support relationships and their dynamics to allow confident hypothesis development. Consequently, the primary purposes of the present study were: (1) to explore relationships among social support, adjustment, and secondary complications of spinal cord injured persons; and (2) to investigate the potential effects of persons' perceptions that they contribute to the social support of others as well as receive social support from others. It was hoped that the study would generate additional data for theory development in social support as well as to discover socialpsychological correlates of adjustment and secondary complications in the SCI population.

\section{Methods}

\section{Subjects}

One hundred and twenty-five persons with a spinal cord injury responded to the SCI Quality of Life Index (QOLI), and the Reciprocal Social Support Scale. Respondents were part of a larger study which included a stratified sample of 572 subjects. All participants had traumatic SCI, were at least 18 years old, and had been injured for at least 1 year at the time of the study. Three stratification criteria were used: (1) race, (2) gender, and (3) age at injury onset. Of the 572 subjects in the larger study, 190 randomly selected subjects were asked to complete the Reciprocal Social Support Scale, and 125 completed it as well as other instruments used in the study.

\section{Instruments}

The Quality of Life Index (QOLI) is a revised version of the Life Situation
Questionnaire (LSQ), ${ }^{8}$ originally developed to collect information on a broad range of variables relevant to persons with SCI. The QOLI incorporates the basic topic areas of the older instrument but has been significantly changed in both item content and format. One of the areas measured by the instrument is current health status, which includes measurement of factors such as functional status and secondary complications. It is this portion of the QOLI that was used for the current project.

The Reciprocal Social Support Scale $(\mathrm{RSS})^{9}$ was designed to assess reciprocal relationships between patients and individuals most likely to be influential members of their social network (spouse, other family members, and friends). In this instrument, measures of social support are operationalized in terms of their functional content (advice, emotional support, social support, and material support) as being active (giving) as well as passive (receiving). For the present study two items were added to measure the extent to which persons saw themselves as being supported by their community and as providing supportive resources to the community.

\section{Procedures}

The Reciprocal Social Support Scale and the SCI Quality of Life Index were mailed to all participants. Follow up mailings and/or calls were made to all nonrespondents. Participants were offered $\$ 5$ as an inducement to complete and return the materials. After analysis of resulting data, 20 persons from the original sample were selected for follow up telephone interviews.

\section{Results}

Pearson correlations were used to identify statistically significant relationships. Although the number of correlations that were significant exceeded chance levels and most of them were potentially psychologically meaningful, most were also of low magnitude, ranging from $r \mathrm{~s}=0.15$ to 0.38 , with only one exception. Most correlations were probably attenuated because of the restricted range of response options-for 
some items the response was 'yes' or 'no' while for others (eg number of events of pneumonia during the previous year) it was unrealistic to have expected much variability. Table I shows significant $(p<0.05)$ correlation coefficients obtained for adjustment and health complications with: (1) patients' reports that they felt supported by their community, (2) patients' reports that they felt they contributed to their community, (3) patients' combined community support scores obtained by adding their ratings for support by and support to the community, and (4) their reports of the frequency of upsetting interactions with family members. Because upsetting events with other persons (ie spouse, friends, and community) showed no significant associations with adjustment and three or fewer significant correlations each with complications, they are not discussed here.

As Table I shows, perceptions of support both from and to the community were correlated with reports of current adjustment and of anticipated adjustment in 5 years. Three complications were associated with support from community; six complications were correlated with perceptions of support given to the community. In order to investigate a nondirectional 'community support' effect, we added patients' scores on the two 7-point scales. The resulting correlation with current adjustment $(r=0.43)$ was stronger than either the 'from' or 'to' coefficients, and the findings were similar for number of days with skin sores and number of hospital admissions.

To explore the community effect further, we divided respondents into low and high groups on the combined community support score, and subjected the resulting scores to analysis of variance. The results, shown in Table II, identified significant group differences on six of the dependent variablescurrent and future adjustment, number of skin sores, number of days of disability from

Table I Correlations of support from and to community, combined community support, and upset (family) with adjustment and complications

\begin{tabular}{|c|c|c|c|c|}
\hline & \multicolumn{3}{|c|}{ Community support } & \multirow{2}{*}{$\begin{array}{l}\text { Upset } \\
\text { (family) }\end{array}$} \\
\hline & From & To & Combined & \\
\hline \multicolumn{5}{|l|}{ Adjustment } \\
\hline Adjustment now & 0.36 & 0.32 & 0.43 & -0.37 \\
\hline Predicted adjustment (5 years) & 0.38 & 0.19 & 0.34 & -0.26 \\
\hline \multicolumn{5}{|l|}{ Complications } \\
\hline Spinal cysts & -0.15 & & & 0.18 \\
\hline Heterotopic ossification & & & & -0.24 \\
\hline \multicolumn{5}{|l|}{ Heart disease } \\
\hline \multicolumn{5}{|l|}{ Diabetes } \\
\hline \multicolumn{5}{|l|}{ Hemorrhoids } \\
\hline No. urinary tract infections & & -0.24 & -0.21 & 0.28 \\
\hline \multicolumn{5}{|l|}{ No. leakage events } \\
\hline \multicolumn{5}{|l|}{ No. constipation events } \\
\hline No. diarrhea events & & & & 0.17 \\
\hline No. skin sores & & -0.29 & -0.23 & 0.34 \\
\hline No. days with skin sores & -0.23 & -0.25 & -0.32 & 0.28 \\
\hline No. doctor visits (skin sores) & & -0.20 & -0.27 & \\
\hline Pain above level of injury & & -0.22 & -0.26 & \\
\hline \multicolumn{5}{|l|}{ Pain below level of injury } \\
\hline \multicolumn{5}{|l|}{ Spasticity } \\
\hline No. doctor visits & & & -0.16 & 0.16 \\
\hline No. hospital admissions & -0.28 & -0.22 & -0.33 & 0.19 \\
\hline No. days in hospital & & & & \\
\hline
\end{tabular}

$p<0.05$ for all correlations reported. 
Table II Analysis of variance: significant differences between groups reporting high and low community support

\begin{tabular}{|c|c|c|c|c|c|}
\hline \multirow[t]{2}{*}{ Variable } & \multicolumn{2}{|c|}{ Group means } & \multirow[t]{2}{*}{$f$} & \multirow[t]{2}{*}{$p$} & \multirow{2}{*}{$\begin{array}{c}\text { Variance } \\
\text { accounted for }\end{array}$} \\
\hline & Low & High & & & \\
\hline Current adjustment & 6.19 & 8.28 & 29.68 & 0.000 & 0.220 \\
\hline Future adjustment & 7.60 & 8.95 & 9.68 & 0.002 & 0.084 \\
\hline No. skin sores & 0.77 & 0.34 & 4.48 & 0.037 & 0.041 \\
\hline No. days with skin sores & 17.30 & 0.70 & 6.42 & 0.013 & 0.058 \\
\hline Pain above level of injury & 1.35 & 0.74 & 10.19 & 0.002 & 0.090 \\
\hline No. hospital admissions & 0.82 & 0.28 & 11.81 & 0.001 & 0.097 \\
\hline
\end{tabular}

skin sores, number of pain events above the level of injury, and number of hospital admissions. The most interesting finding from this analysis was that the significant group difference in reported current adjustment accounted for $22 \%$ of the variance in this item.

Tables III and IV show the significant correlations obtained for adjustment and complications with getting and giving each of the four types of social support identified by the RSS. Getting advice was weakly and positively correlated with current adjustment $(r=0.16)$ and number of hospital admissions $(r=0.17)$ and more strongly and negatively associated with number of diarrhea events $(r=-0.29)$. Giving advice, on the other hand, was significantly associated with seven complications, but not with either of the adjustment measures.

It is tempting to speculate about causal factors for these findings, and some hypotheses fit the data nicely. For example, both receiving and giving emotional support were positively associated with reported days of hospitalization. Having to be hospitalized is discouraging both for a patient and for members of the social network, and it is reasonable to expect that both patient and network members would offer emotional support to the other in order to reduce discouragement and upheaval. Other correlations do not lend themselves so easily to an explanation; for example, the significant relationships of incidents of family upset with heterotopic ossification $(r=-0.24)$ and with the incidence of spinal cysts $(r=0.18)$. While some might argue that such findings are obviously spurious, we believe that they should not be excluded from consideration in view of previously reported counterintuitive relationships among health and psychological variables. ${ }^{10}$

As indicated above, these investigations are exploratory, and causal explanations, however neat, are premature. In this context it is important to note that none of the correlations indicate shared variance of more than about $15 \%$, and are therefore more useful as a basis for speculation about the relationships of health and social support dynamics than as a basis for developing implications for practice.

\section{Follow up interviews}

In order to explore the meaning to subjects of perceived social support from and to the community, 20 persons who had completed the original data were selected for follow up telephone interviews. After establishing their recollection of the previous survey, the interviewer reported to patients their previous ratings of support received from and given to the community, and then asked them to comment on any difference and on their feelings about community support and involvement.

We were interested primarily in patients' explanations about what had caused any difference in their present and previous community support ratings, and in the kinds of activities engaged in by patients who 
Table III Correlations of getting and giving support (advice) and support (social) with adjustment and complications

\begin{tabular}{|c|c|c|c|c|}
\hline & \multicolumn{4}{|c|}{ Type of support } \\
\hline & \multicolumn{2}{|c|}{ Advice } & \multicolumn{2}{|c|}{ Social } \\
\hline & Get & Give & Get & Give \\
\hline \multicolumn{5}{|l|}{ Adjustment } \\
\hline $\begin{array}{l}\text { Adjustment now } \\
\text { Predicted adjustment ( } 5 \text { years) }\end{array}$ & 0.16 & & 0.16 & \\
\hline \multicolumn{5}{|l|}{ Complications } \\
\hline \multicolumn{5}{|l|}{ Spinal cysts } \\
\hline Heterotopic ossification & & -0.32 & & -0.17 \\
\hline Heart disease & & & 0.21 & 0.20 \\
\hline Diabetes & & -0.17 & -0.21 & -0.29 \\
\hline \multicolumn{5}{|l|}{ Hemorrhoids } \\
\hline \multicolumn{5}{|l|}{ No. urinary tract infections } \\
\hline \multicolumn{5}{|l|}{ No. leakage events } \\
\hline \multicolumn{5}{|l|}{ No. constipation events } \\
\hline No. diarrhea events & -0.29 & -0.22 & -0.19 & -0.17 \\
\hline \multicolumn{5}{|l|}{ No. skin sores } \\
\hline \multicolumn{5}{|l|}{ No. days with skin sores } \\
\hline \multicolumn{5}{|l|}{ No. doctor visits (skin sores) } \\
\hline Pain above level of injury & & 0.20 & & \\
\hline \multicolumn{5}{|l|}{ Pain below level of injury } \\
\hline Spasticity & & -0.25 & & -0.18 \\
\hline No. doctor visits & & 0.21 & 0.20 & \\
\hline No. hospital admissions & 0.17 & & & \\
\hline No. days in hospital & & 0.22 & 0.18 & 0.19 \\
\hline
\end{tabular}

$p<0.05$ for all correlations reported.

reported high levels of giving support to the community. An analysis of interview protocols strongly suggested that we are required to develop more carefully-worded questions concerning community support. We discovered that some patients whose 'giving support to community' rating was the highest possible (7), based their reponses not on what they did but on what they felt. For example, one such respondent said, 'I'd like to do something but I'm not sure what I could do', and another said, 'I don't do much of anything but I'd like to do more'. Others who responded less positively to the rating request (ratings as low as 3 ) reported activities in the community such as speaking to school and community groups about the risks of certain behaviors, helping others with transportation to hospitals, serving as a guest preacher, writing letters to politicians and community service groups, and so forth.
Others believed that buying products from local stores was 'giving support to the community'.

It is clear from the variety of responses that we received in this part of our study that we must ask such questions with considerably more precision if we are to obtain useful answers. On the other hand, our statistical findings regarding the relationships of perceptions of getting and giving community support take on added importance in the light of such response variability. As a result, we are increasing our efforts to conceptualize and to define more carefully what is going on. Consistent with our phenomenological approach, for example, is the possibility that patients' perceptions are more powerful than their actual behavior in influencing health status. We must now develop sensitive and reliable measures of such perceptions, of their relationships 
Table IV Correlations of getting and giving material and emotional support with adjustment and complications

\begin{tabular}{|c|c|c|c|c|}
\hline & \multicolumn{4}{|c|}{ Type of support } \\
\hline & \multicolumn{2}{|c|}{ Material } & \multicolumn{2}{|c|}{ Emotional } \\
\hline & Get & Give & Get & Give \\
\hline \multicolumn{5}{|l|}{ Adjustment } \\
\hline Adjustment now & & & 0.26 & 0.19 \\
\hline Predicted adjustment (5 years) & & & 0.25 & 0.21 \\
\hline \multicolumn{5}{|l|}{ Complications } \\
\hline \multicolumn{5}{|l|}{ Spinal cysts } \\
\hline Heterotopic ossification & & & -0.17 & -0.21 \\
\hline Heart disease & & 0.16 & & \\
\hline \multicolumn{5}{|l|}{ Diabetes } \\
\hline \multicolumn{5}{|l|}{ Hemorrhoids } \\
\hline \multicolumn{5}{|l|}{ No. urinary tract infections } \\
\hline No. leakage events & 0.20 & 0.17 & & \\
\hline No. constipation events & & & -0.24 & -0.21 \\
\hline No. diarrhea events & & & -0.37 & -0.24 \\
\hline \multicolumn{5}{|l|}{ No. skin sores } \\
\hline \multicolumn{5}{|l|}{ No. days with skin sores } \\
\hline No. doctor visits (skin sores) & -0.16 & -0.27 & & \\
\hline Pain above level of injury & 0.19 & 0.27 & & \\
\hline Pain below level of injury & & & -0.17 & \\
\hline \multicolumn{5}{|l|}{ Spasticity } \\
\hline No. doctor visits & 0.18 & 0.17 & & \\
\hline No. hospital admissions & 0.16 & & & \\
\hline No. days in hospital & & & 0.23 & 0.23 \\
\hline
\end{tabular}

$p<0.05$ for all correlations reported.

with behavior, and of the dynamics of their effect on patient health.

\section{Conclusions}

The present results with an SCI sample (1) support the conclusion of previous studies that social support is positively related to health; (2) support previous findings ${ }^{8}$ that subjects' perceptions of ability to give, as well as to receive, support are related to a variety of outcomes; and (3) extend the concept of social support from subjects' immediate interpersonal network to the community. We tentatively conclude that the perception of willingness to function in the community can be important to persons with spinal cord injury, and that perception may be more important than behavior, and independent of behavior in affecting health status. The findings suggest that the perception of spinal cord injured individuals that they support, as well as are supported by, members of their social networks and the community in general is related both to health and to adjustment.

Our investigation suggests that among patients with a chronic condition such as spinal cord injury, perceived inability to participate in supportive relationships with the members of one's social network may be an independent risk factor for secondary complications. These observations are inconsistent with the conventional assumption that efficacious social support is that which is received. For example, a common definition of social support is represented by that of Barrera et al, who wrote: 'Social support might be conceptualized as the diversity of natural helping behaviors that individuals actually receive when they are provided with assistance'.11 Our results suggest that a patient's ability to perceive himself or herself not only as a recipient, but also as a source of support to family and friendsand to the community in general-may also contribute significantly to health. 


\section{References}

1 Berkman LF, Syme SL (1979) Social networks, host resistance, and mortality: A nine year follow-up study of Alameda Coutry residents. Am J Epidemiol 109: 186-204.

2 Janis I (1983) The role of social support in adherence to stressful decisions. Am Psychol 38: 143-160.

3 Roy C, Fuqua D (1983) Social support systems and academic performance of single-parent students. School Counsellor 183-192.

4 Tolsdorf C (1976) Social networks, support, and coping: An exploratory study. Fam Process 15: 407-417.

5 Sosa R, Kennell J, Klaus M, Robertson S, Urrutia J (1980) The effect of a supportive companion on perinatal problems, length of labor, and mother-infant interaction. New Engl J Med 303: 597-600.

6 McClellan WM, Anson C, Birkeli K, Tuttle E (1991) Functional status and quality of life: Predictors of early mortality among patients entering treatment for end stage renal disease. J Clin Epidemiol 44: 83-89.

7 Trieschmann R (1988) Spinal Cord Injury: Psychological, Social, and Vocational Adjustment. Demos Publications, New York: 186-196.

8 Krause JS, Crew N (1974) Prediction of long-term survival among persons with spinal cord injury: An 11-year prospective study. Rehabil Psychol 12: 205-213.

9 Anson, C (1987) Social support, locus of control, and change. Unpublished dissertation, Georgia State University.

10 Stanwyck DJ, Anson CA (1986) Is personality related to illness? Cluster profiles of aggregated data. Advances 3(2): 4-15.

11 Barrera M Jr, Sandler IN, Ramsay TB (1981) Preliminary development of a scale of social support: Studies on college students. Am J Community Psychol 9: 435-447. 